\section{Update on Phenobarbital for Alcohol Withdrawal Syndrome in Intensive Care}

\author{
Rukma Parthvi ${ }^{1 *}$ and Parker Agne ${ }^{2}$ \\ ${ }^{1}$ Fellow, Department of Pulmonary, Critical Care and Sleep Medicine, State University of New York, \\ Buffalo, USA \\ ${ }^{2}$ Premed Biochemistry, Department of Chemistry, University of North Florida, USA
}

\begin{abstract}
Alcohol abuse is a global health problem. Alcohol withdrawal syndrome (AWS) ranges from mild to severe symptoms that can lead to fatal delirium tremens requiring ICU admission and incurring high health care cost as high as $\$ 20,000$ a month. The latest published reports suggest that phenobarbital is a promising therapeutic option for management of AWS as evidenced by less ICU admissions, length of stay in hospital, use of adjunctive agents, health care costs and attention from the nursing staff than that of patients treated with commonly used benzodiazepines such as lorazepam, diazepam, and chlordiazepoxide. Phenobarbital is beneficial for the treatment of AWS, both in the emergency and inpatient settings and both as monotherapy or in conjunction with benzodiazepines. It is safe for patients without severe hepatic impairment, has a better mechanism of action and longer half-life than benzodiazepines, and leads to less delirium and agitation. Powered randomized controlled trials with large populations are required, yet phenobarbital can be used to safely to treat AWS.
\end{abstract}

\section{More Information}

*Address for Correspondence: Rukma Parthvi, Department of Pulmonary, Critical Care and Sleep Medicine, State University of New York, Buffalo, USA, Email: rukmapar@buffalo.edu

Submitted: 27 June 2019

Approved: 19 July 2019

Published: 22 July 2019

How to cite this article: Parthvi R, Agne P. Update on Phenobarbital for Alcohol Withdrawal Syndrome in Intensive Care. J Clin Intensive Care Med. 2019; 4: 036-039.

doi:10.29328/journal.jcicm.1001023

Copyright: Parthvi $\mathrm{P}$, et al. This is an open access article distributed under the Creative Commons Attribution License, which permits unrestricted use, distribution, and reproduction in any medium, provided the original work is properly cited

Keywords: Phenobarbital; Alcohol; Withdrawal; Benzodiazepine; Delirium tremens

Check for updates

\section{Introduction}

Alcohol abuse is a global health problem, ranking seventh among the leading causes of death and disability [1]. 2 to $7 \%$ of patients with heavy alcohol use admitted for general medical care develop severe AWS [2]. Symptoms of AWS occur because alcohol is a central nervous system (CNS) depressant. AWS is a fatal medical condition characterized by an imbalance between inhibitory neurotransmitter GABA $(\gamma$-aminobutyric acid) and excitatory neurotransmitter NMDA ( $N$-methyl-D-aspartate) receptor stimulation secondary to chronic ethanol intake [3]. Mild withdrawal symptoms like insomnia, tremulousness, mild anxiety, gastrointestinal upset, anorexia, headache, diaphoresis and palpitations are due to CNS hyperactivity. They usually appear within 6 hours of the last alcoholic drink. Alcohol withdrawal seizures usually occur within 12 to 48 hours after the last drink predominantly in patients with a long history of chronic alcoholism. Such seizures left untreated may develop delirium tremens (DT). Thus, AWS ranges from mild to severe symptoms that can lead to fatal DT requiring ICU admission and incurring high health care cost. Severe AWS is associated with substantial morbidity and mortality [2]. The mortality rate from severe AWS is as high as $20 \%$ if untreated. Early recognition and improved treatment can reduce the mortality rate about $1-5 \%$ [4]. So it requires admission to the emergency department (ED) and proper pharmacologic management [5]. About 15 million Americans suffer from alcohol use disorder, and AWS is a common cause of ED admission [6]. For AWS long-term treatment at a private rehab facility the costs can rise as high as $\$ 20,000$ a month. Programs may last up to 90 days, which can push the costs up to $\$ 60,000$ for a full withdrawal and rehab treatment program [7].

AWS is usually managed with standardized administration of benzodiazepines, supportive care, and continuous evaluation using a validated clinical scale such as the revised Clinical Institute Withdrawal Assessment of Alcohol scale (CIWA-Ar). This protocol of CIWA-Ar-based administration of benzodiazepines has many defects. It puts a heavy burden on the nursing staff, as it requires very frequent monitoring of the patients. Severe AWS accounts for only $10 \%$ of the roughly 500,000 annual cases of AWS episodes that require pharmacologic treatment. Treatment is typically centered on supportive care and symptom-triggered benzodiazepines. But some of these $10 \%$ patients are refractory to benzodiazepines, defined as $>10 \mathrm{mg}$ lorazepam equivalents in 1 hour or $>40 \mathrm{mg}$ lorazepam equivalents in 4 hours [8]. Doses exceeding this threshold provide little benefit and 
put patients at risk for increase morbidity and mortality, over sedation, ICU delirium, respiratory depression and hyperosmolar metabolic acidosis. Many clinicians feel uneasy giving escalating doses of diazepam (starting from 5 $\mathrm{mg}$ and rising to $10 \mathrm{mg}, 20 \mathrm{mg}, 40 \mathrm{mg}$, and even $80 \mathrm{mg}$ per dose) every 5 minutes. The patients often get under-dosed, develop DT and require intubation for airway protection. Large cumulative doses of lorazepam may develop both delirium and respiratory depression. Other drugs like dexmedetomidine and propofol can be used adjunctively to reduce the total amount of benzodiazepines given or to control refractory symptoms. But this may increase cost in the case of dexmedetomidine or require mechanical ventilation in the case of propofol. Therefore, clinicians are always in search of alternative strategies for treating AWS [9]. A simple and practical phenobarbital protocol has yet to be established. The latest published reports and our recent treatment of an 81-year-old patient suggest that phenobarbital to be a promising drug for AWS as evidenced by less ICU admissions, length of stay in hospital, use of adjunctive agents, health care costs and attention from the nursing staff than that of patients treated with commonly used benzodiazepines.

\section{Advantages of phenobarbital over benzodiazepines}

Following are a few potential advantages of phenobarbital over more commonly used benzodiazepines in the treatment of AWS:

Longer Half Life: The half-life of phenobarbital is 80120 hours, compared to lorazepam's half-life of 14-20 hours, with the duration of sedation being very similar between the two drugs: 4-10 hours for phenobarbital and 6-8 hours for lorazepam. Phenobarbital's long half-life helps treat severe AWS and prevents seizures and fatal DT [10]. The long halflife of phenobarbital eases the burden of administration compared with benzodiazepines, which may need to be given more than once per hour. Phenobarbital's long half-life also allows for a gradual transition off of therapy after the last dose is given.

Tapering Effect: Phenobarbital also has a tapering effect as the medication wears off. Therefore, there is no need for additional outpatient prescriptions like chlordiazepoxide [5]. An AWS patient with adequate symptom control after treatment with phenobarbital can be discharged home with no prescriptions. Since these patients do not require a discharge prescription of benzodiazepines to prevent continued withdrawal symptoms, they are protected from the dangers of misuse or overdose of these drugs.

Better Mechanism of Action: Alcohol simultaneously enhances inhibitory tone via modulation of GABA activity and inhibits excitatory tone via modulation of excitatory amino acid activity. Phenobarbital is a barbiturate that, like benzodiazepines and alcohol, targets GABA receptors in the CNS. It is a promising drug for AWS because of its potentiating activity on GABA receptors and its antagonizing activity on $N$-methyl-D-aspartate (NMDA) and $\alpha$-amino-3-hydroxy-5methyl-4-isoxazole propionic acid (AMPA) receptors [11,12]. Its mechanism of action differs from that of benzodiazepines which act solely to potentiate GABA without affecting the increased activity of glutamate on neuronal receptors. In other words, both phenobarbital and benzodiazepines work by inhibiting GABA receptors, but phenobarbital has an additional benefit of suppressing the excitatory glutamate receptors. Therefore, phenobarbital causes less delirium and agitation than that of benzodiazepines.

Safer in Severe AWS: Phenobarbital should be used particularly in case of severe AWS, which is often refractory to benzodiazepines [5]. A loading dose of $10-15 \mathrm{mg} / \mathrm{kg}$ given over 30 minutes is unlikely to lead to serum levels associated with respiratory depression [5]. Phenobarbital, in addition to benzodiazepines, reduces need for mechanical ventilation in the ICU setting and leads to shorter lengths of ICU stay. A loading dose of $10 \mathrm{mg} / \mathrm{kg}$ of phenobarbital, in addition to a lorazepam protocol, significantly reduces ICU admissions (8 vs $25 \%$ ), in contrast to when lorazepam used alone [5].

\section{Phenobarbital doses}

Phenobarbital for AWS can be used in many ways. One way is to use a $10 \mathrm{mg} / \mathrm{kg}$ of ideal body weight loading dose over a 30-minute period. Loading doses are safe when phenobarbital is used alone, but should be used with caution when the patient has received other sedative medications, such as benzodiazepines, as over-sedation can occur [5]. Another approach is to forego the loading dose and give boluses of $130 \mathrm{mg}$ IV over 3 minutes for mild symptoms, or $260 \mathrm{mg}$ IV over 5 minutes for moderate to severe symptoms. Phenobarbital doses of $130 \mathrm{mg}$ can be repeated every 30 minutes as needed and titrated to symptom relief, with a maximum of $1040 \mathrm{mg}$ in 24 hours. Most patients need three doses of phenobarbital for symptoms control, similar to benzodiazepines [13]. In patients thought to have refractory DT, we give phenobarbital 130 to $260 \mathrm{mg}$ IV, repeated every 15 to 20 minutes, until symptoms are controlled. Phenobarbital can also be given orally or intramuscularly, allowing for administration of this drug to patients who lack IV access. It should be avoided in patients with known allergy to barbiturates, and in those with severe hepatic impairment. Patients should always be monitored for respiratory depression during the administration of this drug (Table 1).

\section{Phenobarbital monotherapy}

Tidwell, et al. [14]. In their retrospective cohort study conducted from January 2016 through June 2017 at a 42-bed medical intensive care unit found phenobarbital protocol for AWS treatment as an effective alternative to the standard-ofcare protocol of symptom-triggered benzodiazepine therapy. According to Faust and Westafer [15], phenobarbital monotherapy is easy and works great. Its dosing is far easier 
Table 1: Studies on phenobarbital for alcohol withdrawal syndrome.

\begin{tabular}{|c|c|c|c|c|}
\hline Reference & Aim & Method & Result & Conclusion \\
\hline $\begin{array}{l}\text { Schmidt KJ, Doshi MR, } \\
\text { Holzhausen JM, et al.[3] }\end{array}$ & $\begin{array}{l}\text { To summarize the } \\
\text { literature pertaining to the } \\
\text { pharmacotherapy of severe } \\
\text { alcohol withdrawal }\end{array}$ & $\begin{array}{c}\text { PubMed (January } 1960 \text { to } \\
\text { October 2015) search yielded } \\
739 \text { articles of which } 27 \text { were } \\
\text { included. }\end{array}$ & $\begin{array}{l}\text { Benzodiazepines remain the } \\
\text { treatment of choice, with } \\
\text { diazepam having the most } \\
\text { favorable pharmacokinetic profile. } \\
\text { Propofol is a viable alternative } \\
\text { for patients refractory to } \\
\text { benzodiazepines }\end{array}$ & $\begin{array}{l}\text { The roles of phenobarbital, } \\
\text { dexmedetomidine, and ketamine } \\
\text { remain unclear. }\end{array}$ \\
\hline $\begin{array}{c}\text { Rosenson J, Clements C, Simon } \\
\text { B, et al._[5] }\end{array}$ & $\begin{array}{c}\text { To investigate whether a single } \\
\text { dose of phenobarbital combined } \\
\text { with a standardized lorazepam- } \\
\text { based alcohol withdrawal } \\
\text { protocol decreases ICU } \\
\text { admission }\end{array}$ & $\begin{array}{l}51 \text { patients received a single } \\
\text { dose of phenobarbital ( } 10 \mathrm{mg} / \\
\mathrm{kg} \text { in } 100 \mathrm{~mL} \text { normal saline) } \\
\text { and } 51 \text { placebo ( } 100 \mathrm{~mL} \text { normal } \\
\text { saline) in this prospective, } \\
\text { randomized, double-blind, } \\
\text { placebo-controlled study }\end{array}$ & $\begin{array}{c}\text { Phenobarbital reduced ICU } \\
\text { admissions ( } 8 \% \text { vs. } 25 \%, 95 \% \\
\text { confidence interval } 4-32) \text {. There } \\
\text { were no differences in adverse } \\
\text { events. }\end{array}$ & $\begin{array}{l}\text { A single dose of intravenous } \\
\text { phenobarbital combined with } \\
\text { a symptom-guided lorazepam- } \\
\text { based alcohol withdrawal protocol } \\
\text { decreases ICU admission and } \\
\text { increases adverse outcomes. }\end{array}$ \\
\hline $\begin{array}{l}\text { Hendey GW, Dery RA, Barnes } \\
\text { RL, et al._[13] }\end{array}$ & $\begin{array}{l}\text { To compare phenobarbital (PB) } \\
\text { versus lorazepam (LZ) in the } \\
\text { treatment of alcohol withdrawal }\end{array}$ & $\begin{array}{c}\text { Of } 44 \text { patients, } 25 \text { received PB, } \\
\text { and } 19 \mathrm{LZ} \text { in the ED and at } 48 \\
\text { hours. }\end{array}$ & $\begin{array}{l}\text { Both } P B \text { and } L Z \text { reduced CIWA } \\
\text { scores from baseline to discharge } \\
\text { (15.0-5.4 and 16.8-4.2, } P<.0001) \text {. }\end{array}$ & $\begin{array}{l}\text { PB and LZ were similarly effective } \\
\text { in the treatment of mild/moderate } \\
\text { alcohol withdrawal }\end{array}$ \\
\hline $\begin{array}{c}\text { Tidwell WP, Thomas TL, Pouliot } \\
\text { JD et al._[14] }\end{array}$ & $\begin{array}{l}\text { To compare the benzodiazepine } \\
\text { and phenobarbital protocols }\end{array}$ & $\begin{array}{c}\text { Retrospective cohort study } \\
\text { conducted from January } 2016 \\
\text { through June } 2017 \text { at a } 42 \text {-bed } \\
\text { ICU }\end{array}$ & $\begin{array}{c}\text { Patients who received } \\
\text { phenobarbital had significantly } \\
\text { shorter stays in the ICU than those } \\
\text { who received therapy based on the } \\
\text { CIWA-Ar scale (mean [SD], } 2.4[1.5] \\
\text { vs } 4.4[3.9] \text { days; } P<.001 \text { ). }\end{array}$ & $\begin{array}{l}\text { A phenobarbital protocol for } \\
\text { AWS is an effective alternative to } \\
\text { the standard-of-care protocol of } \\
\text { symptom-triggered benzodiazepine } \\
\text { therapy. }\end{array}$ \\
\hline
\end{tabular}

to keep straight. In case of benzodiazepines or other sedatives it is hard to deciding which one to give, how large a dose and how often. So, the phenobarbital monotherapy protocol is a promising option. In case of patients of AWS alone (i.e., no other active neurologic problem), simply give $10 \mathrm{mg} / \mathrm{kg}$ (ideal body weight) intravenously over 30 minutes. Then wait 30 minutes. If after 1 hour, the patient still requires more medication, give $130 \mathrm{mg}$ (for mild symptoms) or 260 $\mathrm{mg}$ (for moderate to severe symptoms) IV given over 3 to 5 minutes, as needed every 30 minutes. There is little risk till the cumulative dose under $20 \mathrm{mg} / \mathrm{kg}$ IV. Phenobarbital can also be given oral and intramuscular ways. For further detail, $\log$ on to emcrit.org/pulmcrit/phenobarbital-reloaded. There are several benefits of phenobarbital monotherapy (Figure 1) [10].

In case of patients with AWS alone (i.e., no other active neurologic problem), simply give $10 \mathrm{mg} / \mathrm{kg}$ (ideal body weight) intravenously over 30 minutes. Then wait 30 minutes. If after 1 hour, the patient still requires more medication, give $130 \mathrm{mg}$ (for mild symptoms) or $260 \mathrm{mg}$ (for moderate to severe symptoms) IV given over 3 to 5 minutes, as needed every 30 minutes. There is little risk till the cumulative dose under $20 \mathrm{mg} / \mathrm{kg}$ IV. Phenobarbital can also be given orally and intramuscularly. Hence multiple approaches can be taken when using phenobarbital for acute withdrawal syndrome (Figure 2). For further detail, log on to emcrit.org/pulmcrit/phenobarbital-reloaded.

\section{Phenobarbital and hepatic impariment}

Phenobarbitals should be avoided if there's marked hepatic impairment, but it can be safely given to patients with stable alcoholic liver disease. No dose adjustment is required. These patients should be monitored for adverse effects especially signs of hepatic coma. Lower doses should be safe but if higher doses are used there is risk for hepatic encephalopathy, monitoring for hypotension and bradycardia besides other parameters is advised. Most heavy drinkers have steatosis or steatohepatitis. Only 10$15 \%$ end up with cirrhosis [16-18]. That leaves us with good $85-90 \%$ patients with hepatic impairment who can benefit

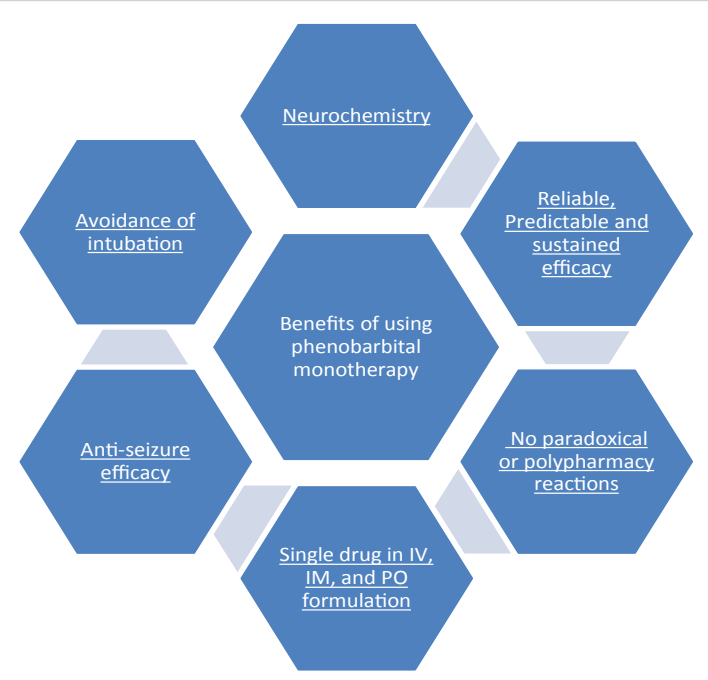

Figure 1: Benefits of using phenobarbital monotherapy in AWS.

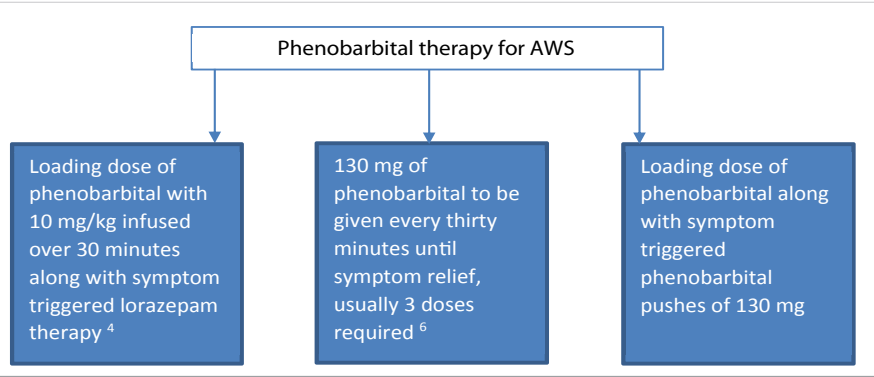

Figure 2: Multiple approaches to using phenobarbital for AWS. 
from phenobarbital even as mono therapy. Others should get phenobarbital in conjunction with benzodiazepines.

\section{Phenobarbital in conjunction with benzodiazepines}

Benzodiazepines increase the frequency of GABA chloride channel opening, and barbiturates such as phenobarbital increase the duration of channel opening. Therefore, they may work synergistically. A number of adjunctive treatments are used to manage patients with refractory DT. Phenobarbital is very effective for AWS patients treated with benzodiazepine [5]. In a randomized trial of 102 patients presenting to the ED with acute AWS, those treated with lorazepam and a single dose of IV phenobarbital had substantially lower ICU admission rates compared with those treated with lorazepam alone (8 versus 25 percent) [5]. Hence multiple approach can be taken when using phenobarbital for acute withdrawal syndrome (Figure 2). Tracheal intubation and mechanical ventilation are frequently necessary if phenobarbital or propofol is used.

\section{Conclusion}

Phenobarbital hits NMDA receptors in addition to GABA. It has many advantages over benzodiazepine-based protocols. Powered randomized controlled trials with large populations are required, yet phenobarbital can be used to safely treat alcohol withdrawal syndrome both as monotherapy and in conjunction with benzodiazepines in the Intensive Care Unit.

\section{References}

1. GBD Alcohol Collaborators. Alcohol use and burden for 195 countries and territories, 1990-2016: a systematic analysis for the Global Burden of Disease Study 2016. Lancet 2018; 392: 1015-1020. PubMed: https://www.ncbi.nlm.nih.gov/pubmed/30146330

2. Wood E, Albarqouni L, Tkachuk S, Green CJ, Ahamad K, et al. Will this hospitalized patient develop severe alcohol withdrawal syndrome? The rational clinical examination systematic review. JAMA. 2018; 320: 825-833. PubMed: https://www.ncbi.nlm.nih.gov/pubmed/30167704

3. Schmidt KJ, Doshi MR, Holzhausen JM. Treatment of severe alcohol withdrawal. Ann Pharmacother. 2016; 50: 389-401.
4. McKeown NJ, West PL. What is the mortality and morbidity of alcohol withdrawal syndrome? Medscape. 2018.

5. Rosenson J, Clements C, Simon B, Vieaux J, Graffman S, et al. Phenobarbital for acute alcohol withdrawal: a prospective randomized double-blind placebo-controlled study. J Emerg Med. 2013; 44: 592598. PubMed: https://www.ncbi.nlm.nih.gov/pubmed/22999778

6. Substance Abuse and Mental Health Services Administration (SAMHSA). 2015.

7. How Much Does Medical Drug and Alcohol Withdrawal Cost? 2019.

8. Hughes D. Benzodiazepine-refractory alcohol withdrawal. Clinical, Critical Care, Toxicology. 2016.

9. Grant BF, Goldstein RB, Saha TD. Epidemiology of DSM-5 alcohol use disorder: results from the National Epidemiologic Survey on Alcohol and Related Conditions III. JAMA Psychiatry. 2015; 72: 757-766.

10. Farkas J. Phenobarbital monotherapy for alcohol withdrawal: simplicity and power. PulmCrit. 2015.

11. Jin $L$, Schlesinger $F$, Song $Y$, Dengler $R$, Krampfl $K$. The interaction of the neuroprotective compounds riluzole and phenobarbital with AMPA-type glutamate receptors: a patch clamp study. Pharmacology. 2010; 85: 54-62. PubMed: https://www.ncbi.nlm.nih.gov/ pubmed/20051697

12. Nejad S, Chuang K, Hirschberg R. The use of antiepileptic drugs in acute neuropsychiatric conditions: focus on traumatic brain injury, pain, and alcohol withdrawal. Int J Clin Med. 2014; 5: 724-736.

13. Hendey GW, Dery RA, Barnes RL, Snowden B, Mentler P. A prospective, randomized, trial of phenobarbital versus benzodiazepines for acute alcohol withdrawal. Am J Emerg Med. 2011; 29: 382-385. PubMed: https://www.ncbi.nlm.nih.gov/pubmed/20825805

14. Tidwell WP, Thomas TL, Pouliot JD, Canonico AE, Webber AJ. Treatment of alcohol withdrawal syndrome: phenobarbital vs CIWAAr protocol. Am J Crit Care. 2018: 27: 454-460. PubMed: https:// www.ncbi.nlm.nih.gov/pubmed/30385536

15. Faust JS, Westafer L. Alcohol withdrawal treatment: bring back phenobarbital? 2018.

16. Phenobarbital dosing, indications, interactions, adverse effects. 2019.

17. Phenobarbital oral solution. 2019.

18. Mann RE, Smart RG, Govoni, R. The epidemiology of Alcoholic liver disease. Alcohol Research \& Health. 2003; 27: 209-213. 